\title{
Análise físico-química e microbiológica da água do rio Grajaú, na cidade de Grajaú - MA
}

\author{
Physicochemical and microbiological analysis of water Grajaú river in the Grajaú city \\ - MA
}

\author{
Santana da Silva Sousa ${ }^{1}$, Wanderson Sousa Silva ${ }^{1}$, João Antônio Leal de Miranda ${ }^{2}$, Jefferson \\ Almeida Rocha ${ }^{1}$ \\ ${ }^{1}$ Grupo de Pesquisa em Ciências Naturais e Biotecnologia (CIENATEC), Universidade \\ Federal do Maranhão (UFMA), Grajaú/MA, Brasil \\ ${ }^{2}$ Departamento de Ciências Biológicas e da Saúde da Universidade Regional do Cariri \\ (URCA), Crato/CE, Brasil
}

\begin{abstract}
Resumo
A cidade de Grajaú conta com o rio Grajaú como fonte de água para o abastecimento da população. A água destinada a consumo humano deve prezar pelo padrão de potabilidade determinado na portaria $n^{\circ}$ 2.914/2011 do Ministério da Saúde. O presente trabalho objetivou avaliar os parâmetros físico-químicos e microbiológicos da água do rio Grajaú, na cidade de Grajaú, MA. Na presente pesquisa foram selecionados seis pontos de coleta da água do rio Grajaú para verificação das características físico-químicas e microbiológicas, tais como: alcalinidade total, cloretos, dureza total, pH, ferro, amônia, cloro, oxigênio consumido, turbidez, cor, coliforme fecais e totais. Os resultados das análises nos seis pontos de coleta do rio Grajaú, evidenciaram que, pelo menos em um dos parâmetros analisados, todos os pontos de coleta da água encontravam-se em fora do valor máximo permitido $(V M P)$, tornando-os impróprios para o consumo humano. Com destaque para o ponto de coleta Limoeiro, que encontra-se fora limites permitidos em quatro parâmetros físico-químico. Ademais, no presente estudo, não evidenciou-se presença de coliforme fecais e totais, em quaisquer dos pontos de coleta avaliados. Assim, este estudo destaca a necessidade de medidas interventivas para controle e adequação dos parâmetros que encontram-se em desacordo com as normativas legais.
\end{abstract}

Palavras-chave: Água; Análise; Físico-química e microbiológica.

\begin{abstract}
The Grajaú city has Grajaú river as a water source to supply the population. Water intended for human consumption must appreciate the potability standard determined in the decree $n^{-}$2.914/2011 of the Ministry of Health. This study aimed to evaluate the physical, chemical and microbiological parameters of the Grajau river water in the Grajaú city, MA. In this study were selected six collection points Grajau River water to check the physicochemical and microbiological characteristics, such as: total alkalinity, chloride, total hardness, $p H$, iron, ammonia, chlorine, consumed oxygen, turbidity, color, fecal and total coliform. The results of the analyzes in the six collection points Grajau river, showed that at least one of the parameters analyzed, all the points of collection of water were in out of the maximum allowed value (PMV), making them unfit for human consumption. Highlighting the point of Limoeiro collection, which is outside the limits allowed in four physicochemical parameters. Moreover, in this study, it did not show up the presence of fecal and total coliform in any of the points of this collection. This study highlights the need for interventional measures for control and adjustment of parameters that are not in accordance with legal regulations.
\end{abstract}

Keywords: Water; Analysis; Physical-chemical and microbiological. Recebido: 02/08/2016 Aceito: 30/08/2016 


\section{Introdução}

Os rios são fontes de um dos recursos naturais indispensáveis aos seres vivos, têm grande importância cultural, social, econômica, histórica da cidade onde se encontram. A origem e manutenção da vida dependem totalmente da água, pois este é o mais abundante componente das células (PONGELUPPE et al., 2009; REIS et al., 2012), recurso insubstituível, compõem aproximadamente $75 \%$ do nosso corpo humano, e o cérebro consiste em cerca de 85\% (YAMAGUCHI, et al., 2013).

Devido suas funções e seu caráter indispensável à vida (CARVALHO, et al., 2009; FREITAS et al., 2013), a disponibilidade de água potável e saudável deve ser acessível a todos (RIGOBELO et al., 2009; MELLO; RESENDE, 2015), sendo de responsabilidade do estado e da nação, devendo o primeiro assegurar que seja feita a gestão adequada dos recursos hídricos, e o segundo de usar o recurso conscientemente (REIS et al., 2012).

Falhas no manuseio da água, principalmente, na maioria dos países em desenvolvimento, onde ainda há carência de saneamento básico, em especial, no tratamento de água tem contribuído para que a qualidade na alimentação diária de parte da população mantenha-se abaixo da considerada ideal (ROCHA et al., 2010). A água em condições de má qualidade, passa a trazer riscos à saúde servindo de veículo para vários agentes biológicos e químicos.

As principais fontes de contaminação através dos recursos hídricos são esgotos de cidades sem tratamento que são lançados em rios e lagos; aterros sanitários que afetam os lençóis freáticos, os defensivos agrícolas que escoam com a chuva sendo arrastados para os rios e lagos, os garimpos que lançam produtos químicos, como o mercúrio, em rios e córregos e as indústrias que utilizam os rios como carreadores de seus resíduos tóxicos, mostrando que tais ações trazem problemas difíceis de serem solucionados (BETTEGA et. al., 2006).

O lançamento de efluentes líquidos e sólidos de origem urbana e industrial nos rios tem grande influência na qualidade da água em que se encontra no rio, afetando a disponibilidade desse recurso natural e gerando graves problemas de desequilíbrio ambiental (LIMA; MEDEIROS, 2008). Segundo a Organização Mundial de Saúde (OMS) estima-se que 25 milhões de pessoas no mundo morrem por ano em virtudes de doenças transmitidas pela água, causadas principalmente por microrganismos patogênicos de origem entérica, animal ou humana, e transmitidos basicamente pela rota fecal-oral.

O propósito primário para a exigência de qualidade da água é a proteção à saúde pública. Os critérios adotados para assegurar essa qualidade têm por objetivo fornecer uma base para o desenvolvimento de ações que, se propriamente implementadas junto à população, garantirão a segurança do fornecimento de água através da eliminação ou redução à concentração mínima de constituintes na água conhecidos por serem perigosos à saúde. (D'AQUILA et. al., 2000).

Legislações específicas referentes à qualidade da água vigoram no Brasil. Entre elas, a Resolução do Conselho Nacional do Meio Ambiente (CONAMA) no 357, de 2005 (BRASIL, 2005), que dispõe sobre a classificação e diretrizes ambientais para o enquadramento dos corpos de água superficiais, estabelecendo limites individuais a cada substância a ser analisada; e as Portarias do Ministério da Saúde no 518, de 25 de Março de 2004 e no 2.914 de 12 de dezembro de 2011, que estabelecem os procedimentos e responsabilidades relativos ao controle e vigilância da qualidade da água para consumo humano e seu padrão de potabilidade (BRASIL, 2005; BRASIL, 2011). Ainda de posse de embasamento jurídico, a Lei 11.445, que estabelece diretrizes nacionais para o saneamento básico, tem como fundamento a universalização do acesso aos serviços de saneamento básico entre eles o abastecimento de água potável (BRASIL, 2007). O que torna o acesso à água potável, livre de micro-organismos patogênicos, de substâncias e elementos químicos prejudiciais à saúde, é direito fundamental de todo cidadão (ZERWES et al., 2015).

Esse estudo objetiva realizar a análise físicoquímica e microbiológica do rio Grajaú da cidade de Grajaú Maranhão, no intuito de analisar as condições de potabilidade da água, visto que está é distribuída para boa parte da população local da cidade, através de um serviço autônomo de água e esgoto (SAAE).

\section{Materiais e Métodos}

\section{Área de estudo}

O estudo foi conduzido no Rio Grajaú, no município de Grajau/MA. Foram selecionados seis para coleta da água do rio Grajaú: Prainha, Ponte de Cimento, depois da Ponte, Canecão, Porto da Nanana e Limoeiro (Figura 01 e Tabela 01) para a realização das análises físico-química e microbiológicas.

As metodologias utilizadas para a determinação dos parâmetros físico-químicos seguiram o modelo do método de investigação empírica, baseado em experimentos para testar, manipular e controlar algumas variáveis do estudo já testado em laboratório. 


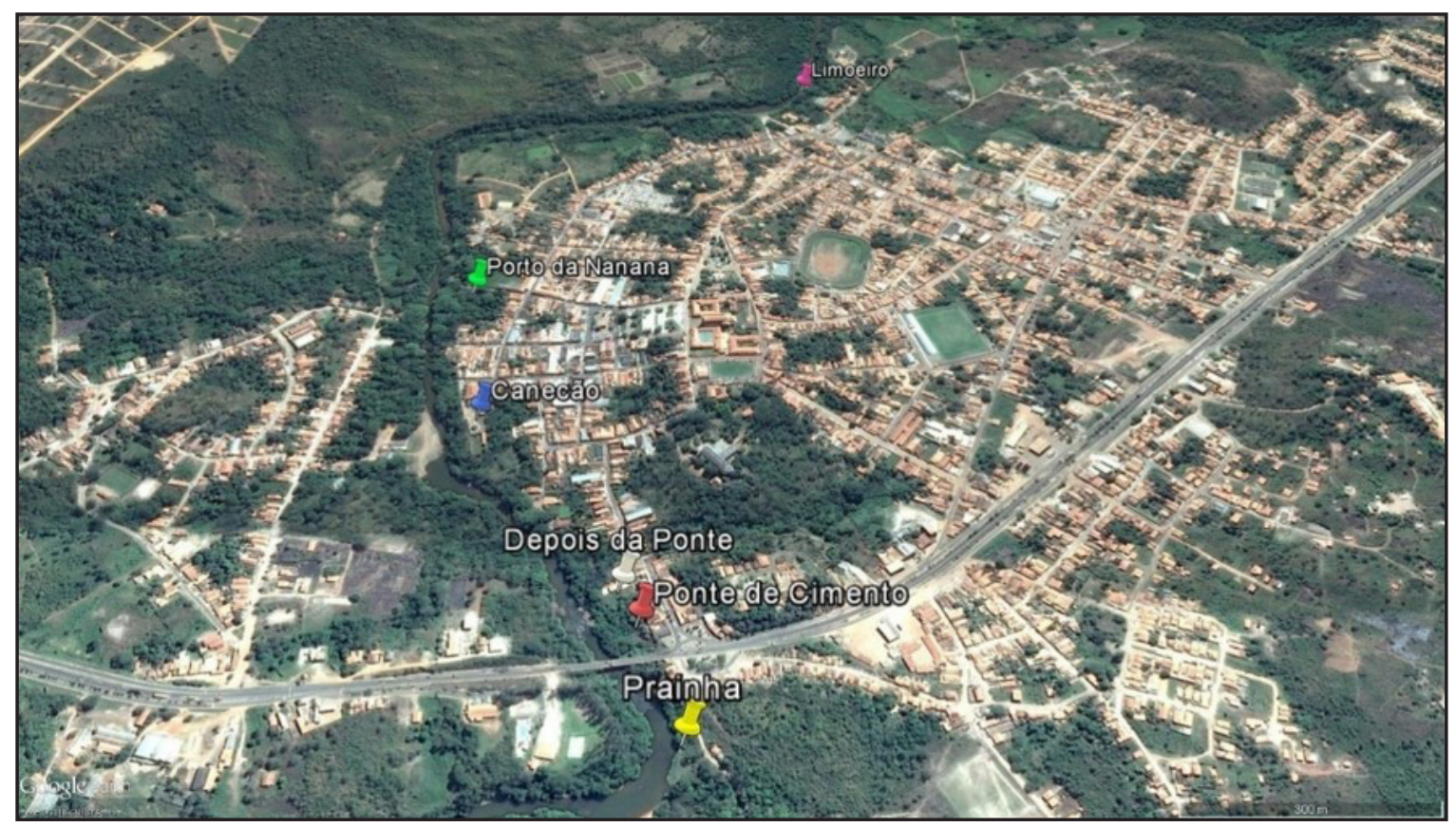

Locais Figura 01 - de coleta identificados ao longo do rio Grajaú - MA.

Tabela 01 - Localização geográfica e altitude dos seis pontos de coleta no rio Grajaú- MA.

\begin{tabular}{|c|c|c|c|}
\hline \multirow{2}{*}{ Locais } & \multicolumn{3}{|c|}{ Coordenadas Geográficas } \\
\hline & Latitude & Longitude & Altitude \\
\hline Prainha & $S$ 05은 $49^{\prime} 28.9^{\prime \prime}$ & W $046^{\circ} 08^{\prime} 26.4^{\prime \prime}$ & $135 \mathrm{~m}$ \\
\hline Ponte de Cimento & S $05^{\circ} 49^{\prime} 23.6^{\prime \prime}$ & W 046 $08^{\prime} 29.2^{\prime \prime}$ & $133 \mathrm{~m}$ \\
\hline Depois da Ponte & S 05은 $49^{\prime} 21.7^{\prime \prime}$ & 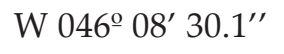 & $133 \mathrm{~m}$ \\
\hline Canecão & $S 05^{\circ} 49^{\prime} 11.1^{\prime \prime}$ & W $046^{\circ} 08^{\prime} 38.0^{\prime \prime}$ & $132 \mathrm{~m}$ \\
\hline Porto da Nanana & S 05은 $49^{\prime} 01.2^{\prime \prime}$ & W $046^{\circ} 08^{\prime} 39.6^{\prime \prime}$ & $132 \mathrm{~m}$ \\
\hline Limoeiro & S 05ㅇ $48^{\prime} 39.9^{\prime \prime}$ & W 046 $08^{\prime} 20.3^{\prime \prime}$ & $131 \mathrm{~m}$ \\
\hline
\end{tabular}

\subsection{Coleta e análise de dados}

As coletas foram realizadas nos meses de novembro de 2015 a janeiro de 2016, no período da manhã, em seis pontos do rio Grajaú (Figura 2). No momento de cada coleta foram registrados os dados geográficos, utilizando GPS Garmin Dakota 20.

As amostras de água coletadas para análise química e microbiológicas foram coletadas em dois recipientes de vidro de $250 \mathrm{ml}$, devidamente identificados e esterilizados em autoclave. Após a coleta, as amostras foram acondicionadas em recipiente térmico para posterior análise em laboratório.

As análises físico-químicas e microbiológicas foram realizadas no laboratório de química da Universidade
Federal do Maranhão, Campus Grajaú. Foram analisados os seguintes itens: alcalinidade total, cloretos, Dureza total, pH, Ferro, Amônia, Cloro, Oxigênio consumido, Turbidez da água, cor e coliforme totais. Para as seguintes análises foi utilizado o kit de potabilidade da Alfakit@, e seguiu-se a metodologia e o protocolo de bancada do referido kit (Tabela 02). Ao fim, de posse dos resultados físico-químico e microbiológicos, realizados em três momentos diferentes (três meses consecutivos), foram extraídas as médias para cada um dos pontos de coleta e, comparadas aos parâmetros obtidos com as definições da Portaria do Ministério da Saúde nº 2.914/2011 (BRASIL, 2011), para a verificação da potabilidade da água do rio Grajaú.

VMP: Valor Máximo Permitido; DPD: Dietil Parafeni- 


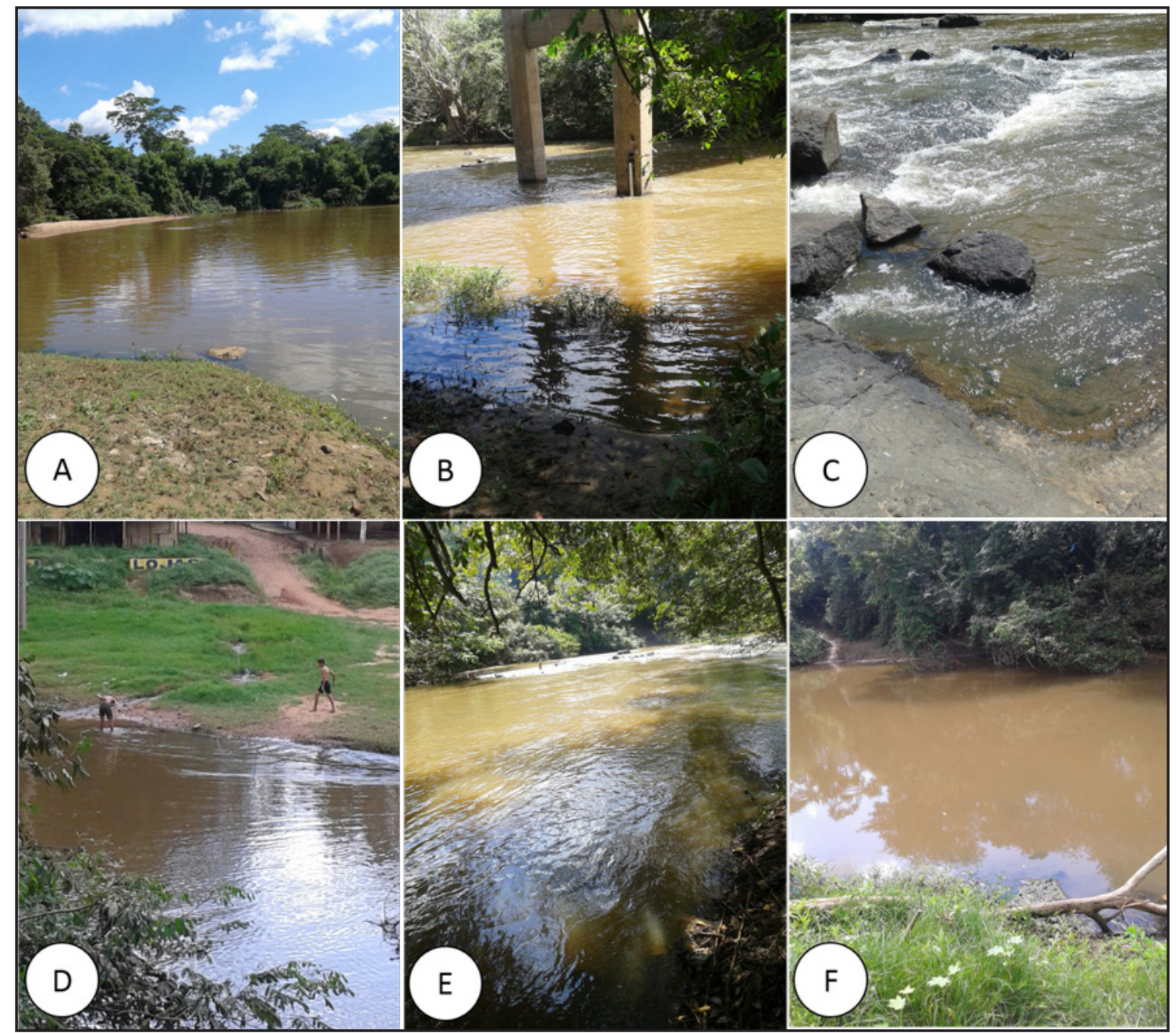

Figura 02 - Rio Grajaú e seus efluentes que são lançados pela cidade de Grajaú - MA. A- Prainha; B- Ponte de Cimento; C- Depois da Ponte; D- Canecão; E- Porto da Nanana e F- Limoeiro.

Tabela 02 - Dados das metodologias adotadas, unidades de medida adotada e valor máximo permitido para análises dos parâmetros físico-químicos e microbiológicos.

\begin{tabular}{|c|c|c|c|}
\hline Parâmetros & Método & VMP & Unidade de Medida \\
\hline Alcalinidade & Neutralização & 500 & mgL-1 CaCO3 \\
\hline Cloreto & Titulação argentimétrica & 250 & mgL-1 Cl- \\
\hline Dureza & Titulação de complexação & 500 & mgL-1 CaCO3 \\
\hline Amônia & Azul de indofenol & 1,5 & mgL-1NH3 \\
\hline Cor & - & 15 & $\mathrm{mgL}-1 \mathrm{Pt} / \mathrm{CO}$ \\
\hline Cloro & DPD & 2,0 & mgL-1 Cl2 \\
\hline Ferro & Ácido tioglicólico & 0,3 & mgL-1 Fe \\
\hline Oxigênio consumido & Oxidação com permanganato & 3,0 & mgL-1 O2 \\
\hline $\mathrm{Ph}$ & Indicador & $6-9,5$ & um. Ph \\
\hline Turbidez & - & 5,0 & NTU \\
\hline Coliforme fecais e totais & $\begin{array}{l}\text { Meio cromogênio em DIP } \\
\text { SLIDE em papel - Colipaper } \\
\text { (Tecnobac) }\end{array}$ & 0,0 & $\mathrm{UFC} / \mathrm{ml}$ \\
\hline
\end{tabular}


leno Diamino; UFC: Unidades Formadores de Colônias.

\section{Resultado e Discussão}

Os resultados obtidos para as amostras testadas nos seis pontos do rio Grajaú, estão representados na tabela 03 e figura 03.

No parâmetro químico alcalinidade total, expresso em mg/L-1 de carbonato de cálcio (CaCO3), nenhum dos seis pontos de coleta no rio Grajaú apresentaram valores acima de $500 \mathrm{mg} / \mathrm{L}-1$ de $\mathrm{CaCO} 3$, ficando na faixa de 93,3 a $190 \mathrm{mg} / \mathrm{L}-1$ de CaCO3. O ponto limoeiro foi o local em que encontrou a alcalinidade em maior nível, 190, respectivamente; já os pontos Canecão e Ponte de Cimento, apresentou os menores índices de alcalinidade, ambos expressando valores de 93,3 mg/L-1 CaCO3. A maioria das águas naturais apresentam valores de alcalinidade na faixa de 30 a 500 mg/L-1 de CaCO3 (BRASIL, 2006; PEREIRA et al., 2010), o que figura a água do rio Grajaú, nos seis pontos analisados, em concentrações moderadas, e dentro da faixa de referência. Portanto, evidenciou-se que água do rio Grajaú, acerca do parâmetro alcalinidade total, não tem nenhum significado sanitário, bem como é incapaz de causar danos à saúde humana.

Do ponto de vista ecológico e ambiental, sabe-se que

Tabela 03 - Média dos Parâmetros Físico-Químicos e microbiológicos dos 6 pontos do rio Grajaú entre os períodos de novembro de 2015 a janeiro de 2016.

\begin{tabular}{c|c|c|c|c|c|c|c}
\hline Parâmetro & Limite & Prainha & $\begin{array}{c}\text { Ponte de } \\
\text { cimento }\end{array}$ & $\begin{array}{c}\text { Depois } \\
\text { da ponte }\end{array}$ & Canecão & $\begin{array}{c}\text { Porto da } \\
\text { Nanana }\end{array}$ & Limoeiro \\
\hline $\begin{array}{c}\text { Alcalinidade (mgL-1 } \\
\text { CaCO3) }\end{array}$ & $* *$ & 96,6 & 93,3 & 96,6 & 93,3 & 106,6 & 190 \\
\hline Cloretos (mgL-1 Cl-) & 250 & 26,6 & 23,3 & 23,3 & 20 & 20 & 40 \\
\hline Dureza (mgL-1 CaCO3) & 500 & 83,3 & 70 & 66,6 & 86,6 & 76,6 & 156,6 \\
\hline Amônia (mgL-1NH3) & 1,5 & 0.1 & 1,5 & 1,5 & 1 & 1 & 1,6 \\
\hline Cor (mgL-1Pt/CO) & 15 & 15 & 15 & 15 & 15 & 15 & 15 \\
\hline Cloro (mgL-1 Cl2) & 2,0 & 1 & 1,5 & 1 & 1 & 1 & 2,5 \\
\hline Ferro (mgL-1 Fe) & 0,3 & 2,5 & 2,5 & 2,5 & 2 & 2,5 & 2,5 \\
\hline $\begin{array}{c}\text { Oxigênio Consumido } \\
\text { (mgL-1 O2) }\end{array}$ & 3,0 & 0,0 & 0,0 & 0,0 & 0,0 & 0,0 & 0,0 \\
\hline PH (um. pH) & $6-9,5$ & 8,0 & 8,0 & 7,8 & 7,5 & 7,6 & 7,6 \\
\hline Turbidez (N.T.U) & 5,0 & 50 & 66,6 & 66,6 & 66,6 & 83,3 & 83,3 \\
\hline Coliforme fecais e totais & 0 & 0 & 0 & 0 & 0 & 0 & 0 \\
\hline
\end{tabular}

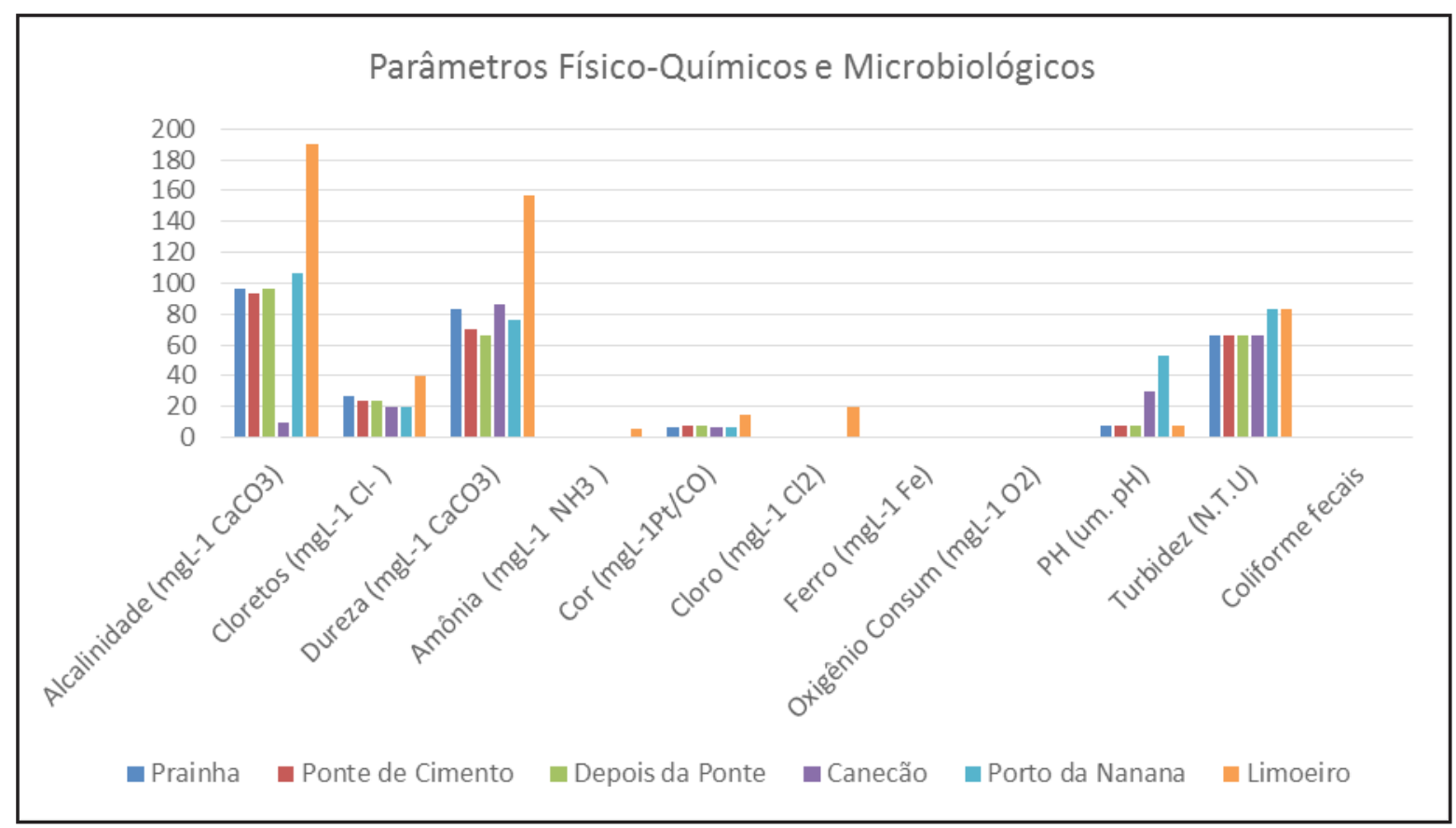

Figura 03 - Média dos Parâmetros e microbiológicos dos 6 pontos do rio Grajau os períodos de novembro de 2015 a janeiro de 2016. 
a medida da alcalinidade é de fundamental importância para se estabelecer a dosagem dos produtos químicos presentes na água (BRASIL, 2006b), pode-se inferir que o rio Grajaú, tem sido preservado pela população, com o controle de efluentes ao longo do rio que são jogados pelo centro da cidade de Grajaú.

Na análise do parâmetro Cloreto, expresso em mgL-1 $\mathrm{Cl}-$, os pontos Canecão e Porto da Nanana obtiveram as menores concentrações de cloreto, apresentando $20 \mathrm{mg}$ $1 \mathrm{Cl}$ - para cada um dos pontos, em seguida, os pontos de coleta Ponte de cimento e Depois da ponte apresentaram valores de $23,3 \mathrm{mg}-1 \mathrm{Cl}-$, em cada um dos pontos analisados, já na ponto Prainha, foi obtido concentrações de 26,6 mg-1Cl- de cloreto, e no ponto Limoeiro, com concentrações de $40 \mathrm{mg}-1 \mathrm{Cl}$, foi o ponto de coleta onde encontrou-se maior concentração de cloreto. De acordo com a portaria no 2. 914 /2011 (BRASIL, 2011), o limite máximo de cloreto estabelecido para água potável é de $250 \mathrm{mg} / \mathrm{L}$, o que torna as amostras dos seis pontos de coleta do rio Grajau, adequado para consumo humano, de acordo com o referido parâmetro físico-químico. Concentrações altas de cloretos podem restringir o uso da água em razão do sabor que eles conferem e pelo efeito laxativo que eles podem provocar, o que não é o caso do rio Grajau, esses resultados, corroboram com os valores obtidos por Pereira et al. (2010) e Zerwes et al. (2015), em ambos os estudos os valores de cloreto encontraram-se abaixo dos limites máximos definidos pela legislação vigente.

Os valores da Dureza total, parâmetro químico e expresso em mgL-1 CaCO3, encontrados nos seis pontos de coleta apresentou significativa variação, com amplitude entre os valores mínimos e máximos de 90 mgL-1 CaCO3. O ponto de coleta Depois da ponte obteve o menor valor de dureza, no qual encontrou-se níveis de 66,6 mgL-1 CaCO3 de Dureza da água, seguido pelos pontos de coleta Ponte de cimento, Porto da Nanana, Prainha e Canecão, com valores de dureza de 70,0, 76,6, $83,3,86,6$, respectivamente; já o ponto de coleta Limoeiro apresentou valores de Dureza elevados em comparação com os demais pontos, onde tal ponto obteve níveis de Dureza de 156,6 mgL-1 CaCO3. A dureza indica a concentração de cátions multivalentes em solução na água. Os cátions mais frequentemente associados à dureza são os de cálcio e magnésio $(\mathrm{Ca}+2, \mathrm{Mg}+2)$ e, em menor escala, ferro $(\mathrm{Fe}+2)$, manganês $(\mathrm{Mn}+2)$, estrôncio $(\mathrm{Sr}+2)$ e alumínio $(\mathrm{Al}+3)$. A origem da dureza das águas pode ser natural (por exemplo, dissolução de rochas calcárias, ricas em cálcio e magnésio) ou antropogênica (lançamento de efluentes industriais) (BRASIL, 2006b; BRASIL, 2014). A dureza da água é classificada em: mole ou branda (<50 mg/L de CaCO3); dureza moderada (50 mg/L a $150 \mathrm{mg} / \mathrm{L}$ de CaCO3); dura $(150 \mathrm{mg} / \mathrm{L}$ a $300 \mathrm{mg} / \mathrm{L}$ de $\mathrm{CaCO} 3)$; e muito dura (> $300 \mathrm{mg} / \mathrm{L}$ de CaCO3) (BRASIL, 2006). Para águas de abastecimento, o padrão de potabilidade estabelece o limite de $500 \mathrm{mg} / \mathrm{L}$ CaCO3 (BRASIL, 2011). No presente trabalho, pode-se determinar que a analisada nos pontos de coleta Depois da ponte, Ponte de cimento, Porto da Nanana, Prainha e Canecão são de dureza moderada e no ponto Limoeiro é considerada dura, além dos mais pode-se inferir que água analisada se encontra nos limites aceitáveis de pela legislação vigente, já que em nenhum dos pontos de coleta obtiveram níveis de dureza igual ou superior a $500 \mathrm{mg} / \mathrm{L} \mathrm{CaCO3}$. De maneira semelhante ao presente estudo, Reda (2016) também encontrou em seu trabalho, grau de dureza abaixo do limite máximo permitido, assim como em Pereira et al. (2010). Manutenção do grau de dureza nos limites aceitáveis é relevante, já que águas de elevada dureza provocam incrustações nas tubulações de água quente, caldeiras e aquecedores, devido à precipitação dos cátions em altas temperaturas, o que é convertido em prejuízo aos sistemas de abastecimentos e, consequentemente a população que faz uso desta água.

$\mathrm{Na}$ análise química de nitrogênio na água do rio Grajaú, obtivemos os seguintes valores de amônia (NH3), expressos em mgL-1 NH3, 0,1 para o ponto de coleta Prainha, 1,0 para os pontos de Canecão e Porto de Nanana, 1,5 para os pontos Ponte de Cimento e Depois da ponte, e 1,6 no ponto de coleta Limoeiro. Segundo a portaria no 2. 914 /2011 (BRASIL, 2011), o valor máximo permitido de amônia é $1,5 \mathrm{mg} / \mathrm{L}$, o que torna a água obtida do Limoeiro imprópria para o consumo humano, e os pontos de coleta Ponto de cimento e Depois da Ponte são considerados críticos, tal que se encontram no limiar permitido. Sabe-se que a além da amônia, outras formas de se avaliar a concentração do elemento nitrogênio podem ser utilizadas, como nitrogênio molecular, nitrito, nitrato (BRASIL, 2014). Ademias, tem se conhecimento que o nitrogênio tem uma significativa origem antropogênica, principalmente em decorrência do lançamento em corpos d'água de despejos domésticos, industriais e de criatórios de animais, assim como de fertilizantes, e propiciam a eutrofização do meio, toxicidade dos peixes que habitam este ambiente, danificação do sistema de abastecimento público (BRASIL, 2006; SCORSAFAVA et al., 2010) e, danos à saúde humana como diurese, dano esplênico e cianose, todos adquiridos com a ingestão de nitratos e nitritos por longo tempo (COSTA et al., 2012). O presente estudo corrobora, com o trabalho de Costa et al. (2012), que também obteve índices de amônia superior ao permitido, e contrasta com Scorsafava et al. (2010), na qual não obteve títulos de amônia acima do valor máximo permitido pela legislação vigente. A partir dos resultados obtidos no trabalho, evidencia-se a necessidade de realizar o monitoramento contínuo e por meio de outras formas, a concentração de nitrogênio nas águas do rio Grajaú, já que o referido rio, serve de abastecimento de água da cidade de Grajaú.

Na avaliação da Cor, parâmetro físico da análise da água, todos os pontos de coletas não apresentaram variação de coloração, correspondendo em todos os locais de coleta a $15 \mathrm{mgL}-1 \mathrm{Pt} / \mathrm{CO}$ ou uH. A cor é um indicador incluído no padrão organoléptico de potabilidade da 
água, e, sua elevação muita das vezes provoca rejeição por parte do consumidor e insegurança no consumo de tal água (BRASIL, 2006b; MELO, 2016). Este parâmetro fornece indícios de contaminação, como a presença de sólidos dissolvidos em suspensão ou material em estado coloidal (orgânicos e/ou inorgânicos); além de poder estar relacionado com a elevada concentração de ferro (SCORSAFAVA et al., 2010). A portaria 2.914/2011, estabelece valor máximo permitido em água para consumo humano de $15 \mathrm{uH}$, o que permite evidenciar que todos os pontos coletados se encontram dentro do padrão de aceitação para consumo, segundo a referida legislação. Assim como no estudo em questão, Scorsafava et al. (2010) e Melo (2016) também encontraram, em todos os locais de coleta, resultados em consonância com a valor máximo permitido, já em Zerwes et al. (2015), apesar da grande maior dos pontos de coleta estarem de acordo com o padrão de potabilidade, evidenciou-se que em um ponto o índice colorimétrico acima do permitido pela portaria.

Na determinação de Cloro Residual livre, expressos em mgL-1C12, os pontos Prainha, Depois da ponte, Canecão e Porto da Nanana, apresentaram 1,0 mgL-1Cl2, em cada um dos pontos, seguido pelo valor encontrado de cloro residual livre na Ponte de cimento, correspondendo a 1,5 mgL-1Cl2, já o ponto Limoeiro apresentou os valores de 2,5 mgL-1Cl2. A portaria no 2.914/2011 recomenda que o teor máximo de cloro residual livre em qualquer ponto do sistema de abastecimento seja de 2,0 mg/l, dessa forma o ponto de coleta Limoeiro encontra-se fora dos níveis permitidos de cloro residual livre, tornando-a imprópria para o consumo humano. $\mathrm{O}$ cloro é um produto químico utilizado na desinfecção da água; sua medida serve para controlar a dosagem que está sendo aplicada e também para acompanhar sua evolução durante o tratamento (BRASIL 2006b). Sabendo que a água analisada em nosso estudo não se trata de água que tenha passado por tratamento, os valores de cloro encontrados são preocupantes, já que nas condições atuais os níveis de cloro residual livre esperados eram abaixo de $0,5 \mathrm{mg} / \mathrm{l}$. Ademias, o resultado obtido no estudo corrobora com Farhadkhani et al. (2014), onde também foi possível observar níveis de cloro residual livre abaixo dos valores estipulados pela portaria vigente. Em Tsega et al. (2013), entretanto, observou-se os níveis de cloro aquém dos valores necessários para uma eficaz desinfecção do sistema de distribuição de água.

A concentração de Ferro, expresso em mgL-1Fe, nos seis pontos analisados apresentaram níveis acima do valor máximo determinado pela portaria $\mathrm{n}^{\mathrm{o}} 2.914 / 2011$, que é de 0,3 mgL-1Fe. Nos pontos Prainha, Ponte de cimento, Depois da ponte, Porto de Nanana e Limoeiro os valores de Ferro foram 2,5 mgL-1Fe, em cada um dos pontos; para o ponto Canecão o valor foi menor que os demais, atingindo o valor de 2,0 mgL-1Fe, contudo, todos os pontos encontram-se fora do padrão de potabilidade, de acordo com este parâmetro. Apesar de não apresentar inconvenientes à saúde nas concentrações normalmente encontradas nas águas naturais (BRASIL, 2006; BRASIL, 2014), o ferro é um parâmetro restritivo na portaria 2.914/2011 (BRASIL, 2011) e, sua determinação é essencial, já que o consumo excessivo de ferro pode causar uma doença chamada hematocromatose, que se caracteriza pelo depósito deste metal nos tecidos de órgãos como fígado, pâncreas, coração e hipófise, além de seu caráter tóxico, devido seu potencial catalítico nas reações de oxidação de lipídios e proteínas. Não somente danos à saúde são observados com os níveis elevados de ferro na água, ele também acarreta problemas de ordem estética (manchas em roupas ou em vasos sanitários), ambientais (com o favorecimento do desenvolvimento das ferrobactéria, dando cor e odor desagradável à água) e, industriais (pela dificuldade de sua retirada pelas estações de tratamento de água bem como oxidação das tubulações de água) (SCORSAFAVA et al., 2010; PEREIRA et al., 2010). Alguns dos motivos da elevação dos níveis de ferro em águas superficiais podem ser devido a erosão das margens dos rios ou advindo dos efluentes industriais da região.

O parâmetro oxigênio consumido trata-se de um método de avaliação indireta da presença de matéria orgânica na água. $\mathrm{O}$ aumento do consumo de oxigênio é um dos problemas mais sérios do aumento do teor de matéria orgânica, já que provoca desequilíbrios ecológicos, podendo causar a extinção dos organismos aeróbicos, com base nisso, fundamenta-se a relevância da monitoração deste parâmetro (BRASIL, 2014). A portaria no 2.914/2011 (BRASIL, 2011), estabelece que os valores máximos permitidos de oxigênio consumido não ultrapassem 3,0 mgL-1O2. O Oxigênio Consumido nos seis pontos de coleta encontra-se dentro dos valores permitidos pela normatização atual sobre potabilidade da água, na qual, em todos os pontos de coletas corresponderam a 0,0 mgL-1O2. O resultado dos níveis de Oxigênio Consumido obtidos no presente estudo é semelhante com os resultados encontrados por Faustino et al. (2013).

O potencial Hidrogeniônico, $\mathrm{pH}$, entre os seis pontos de coleta variou de 7,5 a 8,0, apresentando amplitude de 0,4 entre os dois extremos de $\mathrm{pH}$. O ponto de coleta de menor $\mathrm{pH}$ foi o Canecão, com 7,5, seguido por 7,6 nos pontos Porto de Nanana e Limoeiro; Depois da ponte obteve o pH de 7,8, e nos pontos Prainha e Ponte de cimento o valor do $\mathrm{pH}$ foi de 8,0. Indubitavelmente, $\mathrm{pH}$ é um dos parâmetros mais comumente avaliados nos estudos de padrão de potabilidade, e de excepcional importância, principalmente nos processos de tratamento (BRASIL, 2006b), visto isso, a Portaria do Ministério da Saúde no 2.914/2011 (BRASIL, 2011) recomenda que o $\mathrm{pH}$ da água no sistema de distribuição esteja entre 6,0 e 9,5. Em todas as amostras analisadas, o pH ficou entre os índices recomendados pela legislação brasileira, que não irá causar qualquer efeito prejudicial para a os consumidores. O pH é uma medida da concentração de 
íons de hidrogênio em uma solução, ou seja, expressa o grau de acidez ou basicidade de uma solução, representando a concentração ativa de íons de hidrogênio $(\mathrm{H}+)$ na mesma. Em águas de abastecimento, o pH a afeta, visto que os baixos valores de $\mathrm{pH}$ podem contribuir para sua corrosividade e agressividade, enquanto valores elevados aumentam a possibilidade de incrustações. Assim, o pH da água precisa ser controlado, possibilitando que os carbonatos presentes sejam equilibrados, para que não ocorra nenhuma das consequências citadas (BRASIL, 2006; REDA, 2016; MELO, 2016). Assim como no presente estudo, Strohschoen et al. (2009), Buzelli e Cunha-Santino (2013), Zerwes et al. (2015) e Reda (2016), o pH não ultrapassou os limites recomendados pelo Ministério da Saúde, já em Tsega et al. (2013), alguns locais de coleta valores de $\mathrm{pH}$ inferiores aos limites previstos pela legislação.

A turbidez de água, expressa em unidades de turbidez - uT, também denominadas unidades de Jackson ou unidades nefelométricas de turbidez (NTU), é um indicador sanitário organoléptico de grande importância, já que tal parâmetro contribui para a estética da água e leva a sua aceitação ou rejeição de consumo humano (TSEGA et al., 2016; MELO, 2016), apesar de não ser necessariamente um parâmetro de potabilidade (CUNHA et al., 2012). Contudo, devido sua relevância, a Portaria no ${ }^{2}$ 2.914/2011 do Ministério da Saúde estabelece que o Valor Máximo Permitido é de 5,0 uT como padrão de aceitação para consumo humano (BRASIL, 2006b; BRASIL, 2011). Nos seis pontos de coleta no rio Grajaú, todos encontramse em desacordo com os níveis de turbidez permitidos pela legislação, na qual, a Prainha obteve turbidez de 50 uT, seguido de Ponte de cimento, Depois da ponte e Canecão com 66, 6 uT, e por fim Porto de Nanana e Limoeiro com 83,3 uT. A turbidez pode ser definida como uma medida do grau de interferência à passagem da luz através do líquido. A turbidez dos corpos d'água é particularmente alta em regiões com solos erosivos, onde a precipitação pluviométrica pode carrear partículas de argila, silte, areia, fragmentos de rocha e óxidos metálicos do solo. Grande parte das águas de rios brasileiros é naturalmente turva em decorrência das características geológicas das bacias de drenagem, ocorrência de altos índices pluviométricos e uso de práticas agrícolas, muitas vezes inadequadas. Ao contrário da cor, que é causada por substâncias dissolvidas, a turbidez é provocada por partículas em suspensão, sendo, portanto, reduzida por sedimentação. Além da ocorrência de origem natural, a turbidez da água pode, também, ser causada por ações antrópicas como despejo de esgoto sanitário, efluentes industriais e mineração, fazem com que o escoamento superficial aumente a turbidez da água resultando em grandes alterações no ecossistema aquático (BRASIL, 2006; BRASIL, 2006b; PRATTE-SANTOS et al., 2008; RIGOBELO et al., 2009; SCORSAFAVA et al., 2010; BUZELLI; CUNHA-SANTINO, 2013; BRASIL, 2014; ZERWES et al., 2015). Os resultados elevados de turbidez identificado no presente estudo também foi evidenciado em Pereira et al. (2010), Buzelli e Cunha-Santino (2013), Tsega et al. (2016), sugerindo-se com isso, realização de algum tipo de tratamento antes do consumo dessa água pelas famílias abastecidas por essas águas, objetivando a melhoria do acesso à água de qualidade. Ademias, outras desvantagens são perceptíveis com o aumento da turbidez das águas, como alterações no ecossistema aquático (BUZELLI; CUNHA-SANTINO, 2013) e perdas de cunho financeiro, devido ao entupimento de emissores para irrigação que está diretamente relacionado com a qualidade da água (RIGOBELO et al., 2009).

Em relação ao parâmetro microbiológico, avaliado pela contagem de coliformes fecais e totais, nos seis pontos de coletas do rio Grajaú não foram detectados coliforme fecais e totais. Este resultado microbiológico permite determina que os seis pontos de coleta do rio Grajaú, no período analisado, encontram em conformidade com os padrões de potabilidade estabelecidos pela legislação vigente, a Portaria no ${ }^{\circ}$.914/2011 (BRASIL, 2011), na qual define que a água potável deve estar em conformidade com padrão microbiológico, ou seja, ausência de Unidades Formadores de Colônias (UFC) de coliforme fecais e totais em 100 mL. Apesar de uma grande extensão do rio Grajaú atravessar em centro urbano do município de Grajaú, o que possibilitaria e facilitaria a contaminação do rio com dejetos produzidos pela população, industrias e produtos agrícolas, e consequentemente acarretaria na presença de coliforme fecais e totais, tal fato não foi evidenciado no presente estudo, o que certamente é um fato relevante e positivo na análise do padrão de potabilidade do rio Grajaú, segundo o parâmetro microbiológico. Diversos estudos que realizaram a análise microbiológica de rios e reservatórios, entretanto, encontraram níveis elevados de contaminação com coliforme fecais e totais, tornando tais água, impróprias para consumo humano, animal e balneabilidade (VASCONCELLOS et al., 2006; KOLAREVIĆ et al., 2011; BATISTA; FUCKS, 2012; ANTONY; RENUGA, 2012; FAUSTINO et al., 2013; BUZELLI; CUNHA-SANTINO, 2013; ZERWES et al., 2015); dentre tantos, destaca-se o estudo de Júnior et al. (2014), que ao realizar a análise microbiológica do rio Mearim, no município de Bacabal-MA, evidenciou-se $18.800 \mathrm{UFC} / 100 \mathrm{~mL}$ de coliforme totais e $4.800 \mathrm{UFC} / 100$ $\mathrm{mL}$ de coliforme fecais.

\section{Conclusões}

Na avaliação, como um todo, dos parâmetros físico-químico e microbiológico, nos seis de coleta no rio Grajaú, no período de estudo, permite inferir que tal rio encontra-se fora dos padrões de potabilidade, e, consequentemente, imprópria para o consumo humano, requerendo ainda, de medidas interventivas para controle e adequação dos parâmetros que se encontram em desacordo com as normativas legais. Ademais, com 
verificação rotineira das autoridades de fiscalização cabíveis e conscientização da população do risco à saúde que o consumo de água imprópria acarreta, bem como atividades de educação sanitária à população, como prática efetiva para evitar a contaminação dos mananciais e leitos dos rios, riachos, e demais fontes de água à população.

\section{Agradecimentos}

Os autores gostariam de prestar seus agradecimentos ao curso de Ciências Naturais da Universidade Federal do Maranhão (UFMA) e ao professor colaborador do curso Ciências Biológicas e da Saúde da Universidade Regional do Cariri (URCA).

\section{Referências}

Antony RM, Renuga FB. [Microbiological analysis of drinking water quality of Ananthanar channel of Kanyakumari district, Tamil Nadu, India]. Revista Ambiente \& Água - An Interdisciplinary Journal of Applied Science. [Internet]. 2012 [cited 2016 Jul 25];7 (2): 42-48. Available from: http://www.ambi-agua.net/ seer/index.php/ambi-agua/article/view/881/pdf_650.

Batista BG, Mateus Batista Fucks MB. Avaliação microbiológica da água do Arroio Pessegueirinho de Santa Rosa, noroeste do estado do Rio Grande do Sul. Revista Monografias Ambientais. [Internet]. 2012 [cited 2016 Jul 25];9: 2031-2037. Available from: http:// periodicos.ufsm.br/remoa/article/view/5933/3904.

Bettega JMPR, Machado MR, Presibella M, Baniski G, Barbosa CA. Métodos analíticos no controle microbiológico da água para consumo humano. Ciênc. Agrotec. [Internet]. 2006 [cited 2016 Jul 25];30 (5): 950954. Available from: http://www.scielo.br/pdf/cagro/ v30n5/v30n5a19.pdf.

Brasil. CONAMA. (2005). Resolução no 357, de 17 de março de 2005. Dispõe sobre a classificação dos corpos de água e diretrizes ambientais para o seu enquadramento, bem como estabelece as condições e padrões de lançamento de efluentes, e dá outras providências. Brasília, 2011. Available from: http:// www.mma.gov.br/port/conama/res/ res05/res35705.pdf.

Brasil; Conselho Nacional do Meio Ambiente. Resolução № 357/2005 - Dispõe sobre a classificação dos corpos de água e diretrizes ambientais para o seu enquadramento, bem como estabelece as condições e padrões de lançamento de efluentes, e dá outras providências. Brasília (BRASIL):Conama; 2011. Available from: http:// www.mma.gov.br/port/conama/res/res05/res35705.pdf.
Brasil; Ministério da Saúde. Portaria no 518/2004. Estabelece os procedimentos e responsabilidades relativos ao controle e vigilância da qualidade da água para consumo humano e seu padrão de potabilidade, e dá outras providências. Brasília (Brasil): Ministério da Saúde; 2005. Available from: http://bvsms.saude.gov. br/bvs/publicacoes/portaria_518_2004.pdf.

Brasil; Ministério da Saúde. Portaria nº 2.914/2011. Dispõe sobre os procedimentos de controle e de vigilância da qualidade da água para consumo humano e seu padrão de potabilidade. Brasília (Brasil): Ministério da Saúde; 2011. Available from: http://bvsms.saude.gov.br/bvs/ saudelegis/gm/2011/prt2914_12_12_2011.html.

Brasil. Lei no 11.445/2007. Estabelece diretrizes nacionais para o saneamento básico. Brasília (Brasil). Available from: http://www.planalto.gov.br/ccivil_03/_ato20072010/2007/lei/111445.htm.

Buzelli GM, Cunha-Santino MB. Análise e diagnóstico da qualidade da água e estado trófico do reservatório de Barra Bonita, SP. Revista Ambiente \& Água - An Interdisciplinary Journal of Applied Science. [Internet]. 2013 [cited 2016 Jul 25];8 (1): 186-205. Available from: http://www.scielo.br/pdf/ambiagua/v8n1/14.pdf.

Carvalho DR, Fortunato JN, Vilela AF, Badaró ACL. Avaliação da qualidade físico-química e microbiológica da água de um campus universitário de Ipatinga - MG. Nutrir gerais - Revista Digital de Nutrição. [Internet]. 2009 [cited 2016 Jul 25];3 (5): 417-427. Available from:http:// www.unilestemg.br/nutrirgerais/downloads/artigos/5 edicao/Artigo_AVALIACAO_DA_QUALIDADE_FISICOQUIMICA.pdf.

Costa CL, Lima RF, Paixão GC, Pantoja LDM. Avaliação da qualidade das águas subterrâneas em poços do estado do Ceará, Brasil. Semina: Ciências Biológicas e da Saúde. [Internet]. 2012 [cited 2016 Jul 25];33 (2): 171-180. Available from: http://www.uel.br/revistas/uel/index. php/seminabio/article/viewFile/10469/12164.

Cunha, HFA, Lima DCI, Brito PNF, Cunha AC, Silveira Junior AM, Brito DC. Qualidade físico-química e microbiológica de água mineral e padrões da legislação. Revista Ambiente \& Água - An Interdisciplinary Journal of Applied Science. [Internet]. 2012 [cited 2016 Jul 25]; 7(3): 155-165. Available from: http://www.scielo.br/pdf/ ambiagua/v7n3/v7n3a13.pdf.

D'aguila OS, Roque OCC, Miranda CAS, Ferreira APA. Avaliação da qualidade de Água para abastecimento público do município de Nova Iguaçu. Cadernos de Saúde Pública. [Internet]. 2000 [cited 2016 Jul 25];16 (3): 791-798. Available from: http://www.scielo.br/pdf/csp/ v16n3/2964.pdf. 
Farhadkhani M, Nikaeen M, Adergani BA, Hatamzadeh M, Nabavi BF, Hassanzadeh A. [Assessment of Drinking Water Quality from Bottled Water Coolers]. Iranian J Publ Health. [Internet]. 2014 [cited 2016 Jul 25];43(5): 674-681. English. Available from: http://www.ncbi.nlm. nih.gov/pmc/articles/PMC4449416/pdf/IJPH-43-674.pdf.

Faustino E, Vanzella M, Jesus MA, Meneguetti DUO, Zan RA. Avaliação da qualidade de águas de poços rasos ou comuns da cidade de Ariquemes, Rondônia, Brasil. Revista Científica da Faculdade de Educação e Meio Ambiente. [Internet]. 2013 [cited 2016 Jul 25];4 (2): 65-78. Available from: http://www.faema.edu.br/revistas/ index.php/Revista-FAEMA/article/view/190.

Freitas LL, Silva KC, Souza TM; Demarque ILD, Agostinho L. Fernandes F. Quantificação microbiológica de bebedouros de escolas públicas em Muriaé (MG). Revista científica da Faminas. [Internet]. 2013 [cited 2016 Jul 25];9 (1): 81-93. Available from: www.faminasbh.edu. br/download/baixar/426.

Fundação Nacional de Saúde; Ministério da Saúde. Manual prático de análise de água. 2a ed. [Internet]. Brasília (Brasil): Fundação Nacional de Saúde, 2006b. [cited 2016 Jul 25]. Available from: http://bvsms.saude. gov.br/bvs/publicacoes/manual_analise_agua_2ed.pdf.

Fundação Nacional de Saúde; Ministério da Saúde. Manual de controle da qualidade da água para técnicos que trabalham em ETAS [Internet]. Brasília (Brasil): Ministério da Saúde; 2014 [cited 2016 Jul 25]. Available from: http://www.funasa.gov.br/site/wp-content/files_mf/ manualcont_quali_agua_tecnicos_trab_emetas.pdf.

Júnior FBF, Silva MA, Sampaio JPS, Reis AS, Duarte LHS. Avaliação dos parâmetros da balneabilidade no rio Mearim no município de Bacabal-MA. V Congresso Brasileiro de Gestão Ambiental; 2014 novembro 24-27; Belo Horizonte; MG. BRASIL: IBEAS; 2014. Available from: http://www.ibeas.org.br/congresso/Trabalhos2014/I-054. pdf.

Kolarević S, Knežević-Vukčević J, Paunović M, Gačić Z, Vuković-Gačić B. [Assessment of the Microbiological Quality of the River Tisa in Serbia]. Water Research and Management. [Internet]. 2011 [cited 2016 Jul 25];1 (2): 57-61. English. Available from: http://www.wrmjournal. com/images/stories/casopis/no_02_pdf/Assessment_ Microbiological_Quality_River_Tisa.pdf.

Lima CV, Medeiros GA Diagnóstico da qualidade da água do rio Jaguari-Mirim no município de São João da Boa Vista - SP. Engenharia Ambiental. [Internet]. 2008 [cited 2016 Jul 25];5 (2): 125-138. Available from: http:// ferramentas.unipinhal.edu.br/engenhariaambiental/ viewarticle.php?id=133.
Mello CN, Resende JCP. Analise microbiológica da água dos bebedouros da Pontifícia Universidade Católica de Minas Gerais campus Betim. Revista Sinapse Múltipla. [Internet]. 2015 [cited 2016 Jul 25];4 (1): 16-28. Available from: http://periodicos.pucminas.br/index. php/sinapsemultipla/article/view/9362.

Melo RA. Qualidade físico-química e microbiológica de água fornecida em bebedouros de escolas municipais em Cabedelo-PB. [dissertation].Campina Grande: Universidade Estadual da Paraíba/UEPB; 2016. 104p.

Pereira SFP, Costa AC, Cardoso ESC, Corrêa MSS, Alves DTV, Miranda RG. Condições de potabilidade da água consumida pela população de Abaetetuba-Pará. REA - Revista de estudos ambientais. [Internet]. 2010 [cited 2016 Jul 25];12 (1): 50-62. Available from: proxy.furb.br/ ojs/index.php/rea/article/download/1783/1298.

Pongeluppe AT, Oliveira DB, Silva EA, Aguileira KK, Zitei $\mathrm{V}$, Bastos MF. Avaliação de coliformes totais, fecais em bebedouros localizados em uma instituição de ensino de Guarulhos. Revista Saúde. [Internet]. 2009 [cited 2016 Jul 25];3 (2): 5-9. Available from: http://www.revistas.ung. br/index.php/saude/article/download/257/500.

Pratte-Santos R, Terra VR, Barbiéri RS. Perspectivas da avaliação da qualidade da água em rios por intermédio de parâmetros físicos, químicos e biológicos. Natureza on line. [Internet]. 2008 [cited 2016 Jul 25];6 (2): 63-65. Available from: http://www.naturezaonline.com.br/ natureza/conteudo/pdf/03_pratte-santosretal_6365.pdf.

Reda AH. [Physico-Chemical analysis of drinking water quality of Arbaminch Town]. J Environ Anal Toxicol. [Internet]. 2016 [cited 2016 Jul 25];6 (2): 1-5. English. Available from:http://www.omicsonline.org/open-access/ physicochemical-analysis-of-drinking-water-qualityof-arbaminch-town-2161-0525-1000356.php?aid=70681.

Reis F, Dias CR, Abrahão WM, Murakami FS. Avaliação da qualidade microbiológica de águas e superfícies de bebedouros de parques de Curitiba - PR. Revista Visão Acadêmica. [Internet]. 2012 [cited 2016 Jul 25];13 (1): 55-70. Available from: http://revistas.ufpr.br/academica/ article/viewFile/27400/19404.

Rigobelo EC, Mingatto FH, Takahashi LS, Ávila FA. Padrão físico-químico e microbiológico da água de propriedades rurais da região de Dracena. Revista Acadêmica de Ciências Agrárias e Ambientais. [Internet]. 2009 [cited 2016 Jul 25];7 (2): 219-224. Available from: http://www2.pucpr.br/reol/pb/index. php/academica?dd1=3349\&dd99=view \&dd98=pb.

Rocha ES, Rosico FS, Silva FL, Luz TCS, Fortuna JL. Análise microbiológica da água de cozinhas e/ou cantinas 
das instituições de ensino do município de Teixeira de Freitas (BA). Revista Baiana de Saúde Pública. [Internet]. 2010 [cited $2016 \mathrm{Jul}$ 25];34 (3): 694-705. Available from: http://inseer.ibict.br/rbsp/index.php/rbsp/article/view/66.

Secretaria de Vigilância em Saúde; Ministério da Saúde. Vigilância e controle da qualidade da água para consumo humano. Série B. Textos Básicos de Saúde [Internet]. Brasília (Brasil): Ministério da Saúde; 2006 [cited 2016 Jul 25]. Available from: http://bvsms.saude.gov.br/bvs/ publicacoes/vigilancia_controle_qualidade_agua.pdf.

Scorsafava MA, Souza A, Stofer M, Nunes CA, Milanez TV. Avaliação físico-química da qualidade de água de poços e minas destinada ao consumo humano. Rev Inst Adolfo Lutz. [Internet]. 2010 [cited 2016 Jul 25];69 (2): 229-32. Available from: http://ses.sp.bvs.br/lildbi/ docsonline/get.php?id=1801.

Strohschoen AAG, Périco E, Lima DFB, Rempel C. Estudo preliminar da qualidade da água dos rios Forqueta e Forquetinha, Rio Grande do Sul. R. bras. Bioci. [Internet]. 2009 [cited $2016 \mathrm{Jul}$ 25];7 (4): 372-375. Available from: http://www.ufrgs.br/seerbio/ojs/index.php/rbb/article/ download/1227/892.

Tsega N, Sahile S, Kibret M, Abera B. [Bacteriological and physico-chemical quality of drinking water sources in a rural community of Ethiopia]. African Health Sciences. [Internet]. 2013 [cited 2016 Jul 25];13 (4): 1156-1161. English. Available from: http://www.ncbi.nlm.nih.gov/ pmc/articles/PMC4056515/pdf/AFHS1304-1156.pdf.

Vasconcellos FCS, Iganci JRV, Ribeiro GA. Qualidade microbiológica da água do rio São Lourenço, São Lourenço do Sul, Rio Grande do Sul. Arq. Inst. Biol. [Internet]. 2006 [cited 2016 Jul 25];73 (2): 177-181. Available from: http://www.biologico.sp.gov.br/docs/arq/V73_2/ vasconcellos.PDF.

Yamaguchi UM, Lúcia ERC, Lilian CCO, Jully O. Qualidade microbiológica da água para consumo humano em instituição de ensino de Maringá-PR. O Mundo da Saúde. [Internet]. 2013 [cited 2016 Jul 25];37 (3): 312320. Available from: http://www.saocamilo-sp.br/pdf/ mundo_saude/106/1827.pdf.

Zerwes CM, Secchi MI, Calderan TB, Bortoli J, Tonetto JF, Toldi M. Análise da qualidade da água de poços artesianos do município de Imigrante, Vale do Taquari/ RS. Ciência e Natura. [Internet]. 2015 [cited 2016 Jul 25]; 37 (4): 651-663. Available from: http://periodicos.ufsm. br/cienciaenatura/article/view/17385. 